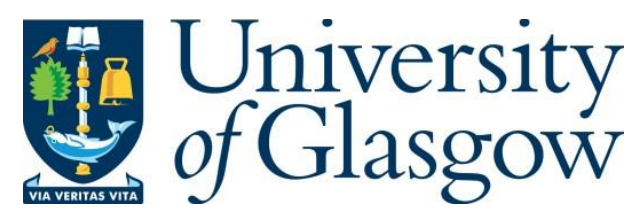

Forbes, A. (2018) Lungworm in cattle: epidemiology, pathology and immunobiology. Livestock, 23(2), pp. 59-66.

There may be differences between this version and the published version. You are advised to consult the publisher's version if you wish to cite from it.

http://eprints.gla.ac.uk/159148/

Deposited on: 28 March 2018

Enlighten - Research publications by members of the University of Glasgow http://eprints.gla.ac.uk 


\title{
Lungworm in Cattle: Epidemiology Pathology and Immunobiology
}

Andrew Forbes. Scottish Centre for Production Animal Health and Food Safety, School of Veterinary Medicine, University of Glasgow, G61 1QH

\begin{abstract}
The bovine lungworm, Dictyocaulus viviparus, causes disease in all ages of cattle and in addition to having a self-evident effect on animal welfare, it can have a considerable economic impact at farm level, even with subclinical infections. Whilst most clinical cases are seen in cattle at pasture from July until housing, occasional outbreaks occur in housed cattle that have been infected previously at grass, or occasionally from infections acquired from forage or low-level cycling in straw yards. Whilst the overall seasonal pattern of infection is consistent over large temporal and spatial scales, there is marked year-to-year and within season variability in the number of cases seen at both regional and farm levels. This relative unpredictability can bring uncertainty to decisions on control. In order to be able to provide sound, evidence-based advice on treatment and control to farmers, it is important that clinicians grasp important, practically relevant aspects of lungworm biology, pathology, immunity and epidemiology: the aim of this article is to do just that. A second article describes and analyses the options for prevention and treatment of husk, based on this knowledge.
\end{abstract}

Key words: Dictyocaulus viviparus, epidemiology, pathology, immunology, re-infection syndrome

\section{Introduction}

The lungworm of cattle, Dictyocaulus viviparus, is the cause of a serious, sometimes fatal, respiratory disease of cattle of all ages, known as parasitic bronchitis (PB) or verminous pneumonia and colloquially as husk in Britain and hoose in Ireland. Although the parasite is present in continental Europe, North America and Australasia, its impact appears to be most evident in north-east Europe where infection rates in dairy herds, based on bulk tank milk $D$. viviparus antibody concentrations, range from 3\% in Switzerland (Frey et al., 2018) to 17\% in Germany, 20\% (Schunn et al., 2013) in Belgium (Bennema et al., 2009), 63\% in Ireland (Bloemhoff et al., 2015) and 80\% in the Netherlands (Ploeger et al., 2012). Sero-epidemiological surveys in first grazing season (FGS) calves in Germany (dairy) and Sweden (dairy and beef) showed farm prevalence of $\sim 40 \%$ (Hoglund et al., 2004; Schnieder et al., 1993).

Although outbreaks of parasitic bronchitis in the United Kingdom (UK) have an underlying seasonal pattern (Figure 1), with most cases being reported in late summer and autumn (APHA, 2016), infection is subject to large regional and temporal fluctuations and the risk of disease is much less predictable than parasitic gastroenteritis, which occurs concurrently in cattle at pasture. Occasional cases of husk have been reported in calves that have never been at grass and in housed cattle, possibly through acquiring infection soon after birth or from being fed cut grass or from limited cycling of infection in the bedding (Crawshaw and Smith, 2003). This article, the first of two, aims to complement and extend the review article previously published in Livestock (Tilling, 2014), initially with a focus on epidemiology, pathology and immunobiology, drawing on some of the seminal studies conducted over the last 65 years, linked with the results of some recent research on lungworm.

\section{Larval Ecology and Epidemiology}


D. viviparus infection persists from one year to the next on farms through two main avenues (Jarrett et al., 1957a):

- On pasture (herbage $\&$ soil) as infective third stage larvae (L3)

- In 'carrier' animals, commonly as inhibited L4, which develop to adult lungworms in spring

When animals are turned out in the spring they may encounter lungworm through ingestion of L3 on pasture that was grazed by infected cattle the previous year or, if grazing with carrier animals, through acquisition of larvae that have been deposited on the herbage following re-activation of inhibited larvae to develop into egg-laying adults at the end of winter (Eysker et al., 1994). The freeliving larval stages of $D$. viviparus do not feed and develop into infective (L3) rapidly: in less than a week under optimal conditions (Rose, 1956). Absence of feeding may explain why they appear to be relatively inactive as presumably they have to conserve their limited energy resources; nonetheless, although infective larvae may only survive for a few weeks on pasture under warm, dry conditions, somewhat paradoxically, they can survive for over a year, even when the fields have been used to make hay in the interim (Duncan et al., 1979; Nelson, 1977; Oakley, 1977).

Larval sluggishness also explains why indirect means of translocation from the dung pat onto the surrounding vegetation are so important, for example through the agency of dung-associated fungus of the genus Pilobolus (Doncaster, 1981; Robinson, 1962) (Figure 2). Pilobolus species are common coprophilous fungi; fungal spores pass through the digestive tract of herbivores in the dung, where they germinate and subsequently produce sporangiophores within $\sim 1$ week. In the middle of the day, the sporangiophores propel sporangia, along with any lungworm larvae that have climbed up the sporangiophores on to the sporangium (Doncaster, 1981). The interaction between lungworm and Pilobolus spp. is not just a neat example of some interesting biology, but is important in the epidemiology of dictyocaulosis as it has been shown that translocation of $L 3$ over distances of $\geq 100$ $\mathrm{cm}$ from the dung pat to the surrounding herbage was reduced by $>90 \%$ in the absence of the fungus (Jorgensen et al., 1982). In addition, movement of larvae over longer distances within or between fields through passive transport of faeces on hooves and on farm implements has been demonstrated (Rose and Michel, 1957; Spedding and Michel, 1957).

The relative importance of carrier animals in the epidemiology of dictyocaulosis varies regionally; in the United Kingdom (UK) over-winter larval survival is important in the maintenance of infectivity of pastures from year to year, though $31 \%$ of yearlings (stirks) and $4 \%$ of cows examined in late winter harboured small numbers of adult lungworms (Cunningham et al., 1956). In the Netherlands carrier animals are considered to be pivotal in lungworm epidemiology (Saatkamp et al., 1994), whilst overwinter survival on pasture appears to be inconsequential there. The importance of carrier animals has been utilised in attempts to eliminate $D$. viviparus from dairy farms through herd treatment preturnout to remove all lungworm from older cattle (Ploeger and Holzhauer, 2012). Despite the negative title of this paper, in fact infection and disease was prevented for over a year on one farm and for at least four years on the other. Irrespective of regional variations, it should be remembered that mixed-age grazing groups of cattle constitute a risk factor for husk (Forbes, 2017) because of the potential mixing of carrier animals with naïve youngstock (Gupta and Gibbs, 1970).

The pre-patent period of $D$. viviparus is 3-4 weeks and female lungworms are highly fecund; most estimates of daily egg production and hence larvae (L1) range from 1000 to 25,000 per female per day (Ploeger and Eysker, 2000), with $~ 10,000 /$ female/day being a useful average for theoretical 
calculations. Thus even cattle carrying relatively small $(<50)$ burdens of adult worms can be seeding the pastures with millions of $\mathrm{L} 1$ each day. Consequently, because development to $\mathrm{L} 3$ can take place in less than a week, pasture larval populations can increase very rapidly. Despite the ability of L3 to survive over-winter and for longer, under warm, dry conditions on pastures with a short sward, survival can be quite short - just a few weeks - and this can lead to large fluctuations in pasture larval populations (Jorgensen, 1980b), as illustrated in Figure 3. If a $250 \mathrm{~kg}$, FGS calf is considered as an example, its forage intake is of the order of $5 \mathrm{~kg}$ dry matter (DM) per day (Forbes et al., 2000), so if it is grazing a pasture with 1600 L3/kg DM (Jorgensen, 1980b), it could ingest 8000 D. viviparus L3 per day. The establishment rate of these larvae in the lungs of naïve animals is $~ 30 \%$ (Ploeger and Eysker, 2000), thus an adult burden of 2400 worms could be acquired from one day's ingestion of L3; such burdens are associated with clinical disease and fatal outcomes (Jarrett et al., 1957a; Michel and Parfitt, 1956).

\section{Pulmonary stages and Pathogenesis}

Following ingestion, infective larvae become more active in the presence of bile in a microaerophilic atmosphere (Jorgensen, 1980a) and traverse the wall of the small intestine, enter the lymphatic system and the mesenteric lymph glands after around four days and are thence transported via the thoracic duct and the circulation to the lungs, reaching them within a week post-infection (Jarrett et al., 1957b). Here the larvae colonise the alveoli initially and subsequently enter the bronchioles, ending up as adults in the major bronchi or base of the trachea (Figure 4). The parasites undergo a remarkably rapid growth phase at this time; entering the lungs as larvae a few millimetres in length, developing in to adult worms several (3-8) centimetres in length 3-4 weeks later (Laabs et al., 2012). During colonisation of the lungs, marked inflammatory changes are invoked in the alveoli and bronchioles with accumulations of eosinophil-rich mucus and parasite debris (Schnieder et al., 1991). Alveolar pathology includes epithelialisation with the normal cell architecture replaced by undifferentiated cells, which are incapable of gaseous exchange, rendering affected alveoli incompetent (Jarrett et al., 1954).

Alveolar epithelialisation appears to be irreversible and may account for some 'treatment failures', when removal of the parasites does not lead to a resolution of clinical signs (Jarrett et al., 1957b). Another feature of the pathology of husk is a loss of ciliated epithelial cells in the bronchi (Schnieder et al., 1991) and this would be expected to render the host more susceptible to other respiratory pathogens. Though this is commonly assumed by clinicians and may form the basis for precautionary administration of antibiotics in some cases of husk, there is limited and equivocal scientific evidence to support this practice. In calves infected with D. viviparus and subsequently challenged with Respiratory Syncytial Virus (RSV), clinical signs were more pronounced in the co-infected animals compared to those infected with RSV alone (Verhoeff et al., 1988). In animals latently infected with bovine herpes virus I (IBR), recrudescence of infection followed a moderately high challenge (50 $\mathrm{L3} / \mathrm{kg}$ ) with $D$. viviparus (Msolla et al., 1983). In contrast the frequency of bacterial isolation and the severity of pathology in calves infected with Pasteurella haemolytica were not exacerbated by subsequent infection with $D$. viviparus, even though severe PB developed in these animals (Shoo et al., 1990).

\section{Host-parasite interactions}


Immune responses play a central role in dictyocaulosis both in terms of host susceptibility and the manifestations of disease. The immune response is essentially biphasic (Kooyman et al., 2007; Michel, 1962; Michel and Mackenzie, 1965) and has been summarised elsewhere (Forbes, 2012) and below:

- Phase 1: After ingested larvae have left the intestinal tract, they reach the mesenteric lymph glands en route to the lungs. There an immune response is initiated, which destroys the majority of larvae in situ and prevents them from reaching the respiratory tract. This response is initiated rapidly within 2 weeks of a primary infection, but is short-lasting and protection declines markedly over the subsequent 6 months if no further exposure occurs.

- Phase 2: Larvae that evade the immune response in the mesenteric glands reach the respiratory tract a secondary immune response is invoked, which results in the destruction and elimination of parasites from the lungs. In contrast to the phase 1 response, this $2^{\text {nd }}$ phase response in the lungs lasts for two years or more, even in the absence of any challenge.

Protective immunity can be induced after as little as 10 days development in naïve hosts, though the magnitude of the response is dose-dependent (Ploeger and Eysker, 2002) and if cattle experience only a small challenge, they can develop patent infections without acquiring a fully protective immunity and hence can succumb to a later challenge on the same pasture from auto-infection through ingestion of high concentrations of larvae derived from the first generation of parasites (Jorgensen, 1980b).

The re-infection syndrome occurs when the effectiveness of the phase 1 response has declined through lack of exposure. On re-exposure, larvae reach the lungs where they encounter the Phase 2 response. If numerous larvae reach the lungs they will be killed and eliminated, but in the process, the resulting immunopathology can cause respiratory signs that can resemble those of patent $D$. viviparus infection (Michel and Coates, 1958). This explains why the re-infection syndrome is often seen 10-14 days after a move to a new pasture and why lungworm larvae are rarely found in faecal samples from adult cows at pasture unless they are naïve and undergoing a primary lungworm infection (or are carriers in which inhibited larvae have resumed development).

\section{Lungworm in adult cows}

"Whether the incidence of husk in adult cattle has increased in recent years is difficult to determine" is not a recent quote, as some may assume, but these are the opening lines from a paper published in 1955 (Michel and Shand, 1955). Nonetheless, although accurate estimates of the prevalence of PB in adult cattle are lacking, evidence from passive surveillance indicate that the increase in diagnoses of dictyocaulosis since 1993, illustrated in a recent review (McLeonard and Van Dyk, 2017), comprise an increase in the proportion of submissions involving adult cattle (David, 1993). If there is a real increase in the occurrence of husk in cows, what are the possible reasons? A popular notion is that a reduction in the use of lungworm vaccination and greater reliance on anthelmintics in the control of PB are to blame (McLeonard and Van Dyk, 2017), however, supporting scientific evidence for this is sparse. It is quite plausible that having fewer animals in the national herd with a predictable immunity to $D$. viviparus through vaccination means that enzootic instability is now more common and thus mismatches between host immunity and larval challenge could precipitate outbreaks of patent lungworm infections or the re-infection syndrome in cows (David, 1997). 
With respect to the potential for anthelmintic use in youngstock to be a risk factor for dictyocaulosis in cows, there is quite a large body of research in the peer-reviewed literature. For example in the decade between 1988 and 1998, numerous relevant field studies can be found in which immunity to lungworm was assessed following the strategic use of anthelmintics (including boluses); one of the later papers is cited as it provides references to several of these studies (Schnieder et al., 1996). The immune status of anthelmintic-treated groups was assessed through clinical and serological monitoring and, in eight studies by artificial challenge with $D$. viviparus infective larvae after housing at the end of the grazing season. In all but one bolus-treated group in one study (Taylor et al., 1997), post-challenge lungworm burdens in anthelmintic-treated animals were consistently much reduced compared to those in naïve controls and were generally similar amongst peer groups exposed to various strategic regimes or in untreated controls. In some studies there was an inverse relationship between the effectiveness of the anthelmintic regime in controlling lungworm infection and the level of protective immunity (Borgsteede et al., 1998). Also of interest is the observation that cattle exposed to natural lungworm challenge (Forbes and Rice, 2000) or induced infections (Taylor et al., 2000) can seroconvert to $D$. viviparus in the presence of effective concentrations of anthelmintic.

The lack of evidence for strategic anthelmintic use in the first grazing season being a major risk factor for PB in older cattle is further supported by some epidemiological observations that failed to find any significant, consistent associations between anthelmintic use in FGS cattle and dictyocaulosis in cows (David, 1997; Ploeger et al., 2000). Whilst there are limited supportive data for their role as risk factors, there are a number of changes in dairy herd management that have occurred over the last 25 years or so, which could have affected the epidemiology of dictyocaulosis, potentially increasing the incidence, particularly in dairy cows. These include:

- Heifers calving at two years

- Less time spent at grass pre-calving; fewer opportunities for exposure to $D$. viviparus

- Heifers being raised on separate pastures remote from the adult dairy herd (David, 1997; Michel and Ollerenshaw, 1963)

- On their farms of birth

- Contract rearing on different farms

- Heifers being raised inside until pregnant, then turned out to graze at $\sim 18$-months of age

- Year-round calving (AYR) herds

- Wide range of ages of youngstock at any one time

- Different turnout dates and duration of time spent at grass up to first calving, depending on month of birth (Michel, 1957)

- Vaccination protocol can only applied to some cohorts of FGS calves (autumn/winter-born)

- Strategic anthelmintic programmes can only applied to some cohorts of FGS calves

- Spring-calving dairy herds managed intensively on grass-based systems

- Calves put out to grass at a young age, sometimes pre-weaning

- Most calves too young to enrol in vaccination programme (before turnout)

- Not an ideal fit for strategic use of anthelmintics in FGS

- High frequency rotational grazing in milking herd with return to previously grazed pasture within a few weeks 
From knowledge of the biology, epidemiology and immunobiology of $D$. viviparus, it can be deduced that the changes in husbandry listed above could individually or collectively lead to enzootic instability and consequently outbreaks of PB, particularly in older animals. In addition, lack of appropriate quarantine measures could result in:

- The introduction of naïve animals into an endemically infected herd

- The introduction of infected (carrier) animals into a naïve herd

Both of these were associated with outbreaks of PB (David, 1997).

\section{Monitoring and Diagnosis of Husk}

In the absence of preventative control measures for lungworm, a common and recommended approach is 'vigilance and treatment' (Michel, 1969). This practice requires that the farmer or stockperson can detect clinical signs and either initiate treatment or alert the veterinary clinician quickly if he/she suspects husk or hoose to be affecting their cattle.

\section{Youngstock}

The appearance of coughing, tachypnoea ( $\geq 50$ breaths/minute) and ill thrift in (naive) calves or yearlings in the second half of the grazing season can be regarded as almost pathognomonic for husk (Jarrett et al., 1957a), so clinical dictyocaulosis would be strongly suspected if one or more of the follow criteria are satisfied:

- July to October

- Permanent pasture previously grazed by (older) cattle

- Mixed grazing with older cattle

- No lungworm vaccination or strategic anthelmintic use

- Loss of appetite and poor growth rates (Boon et al., 1984; Kroonen et al., 1986)

- Coughing and/or tachypnoea in several individuals, particularly when disturbed, in a group of animals

- Death (Downey, 1965)

Lungworm larvae present in any faecal samples from $\sim 10$ animals is confirmatory, but negative findings do not eliminate husk as infection may still in the pre-patent period: re-sampling 7-10 days later can confirm. If PB has been ruled out, then differential diagnosis for other respiratory pathogens should be carried out.

Adult dairy cows

Lungworm in adult cattle would be considered under circumstances including the following:

- July to October

- Mixed grazing with younger cattle

- Heifers or bought-in animals added to herd over the grazing season

- Recent move to a new field

- No lungworm booster vaccinations

- Coughing and tachypnoea in some individuals (Wapenaar et al., 2007) 
- Dull, depressed individuals, loss of appetite (Michel and Shand, 1955)

- Sudden drop in daily individual and/or bulk tank milk yield

- Apparent sudden death (SAC, 2018)

Although some cows with PB are in very obvious respiratory distress (Figure 5), confirmation of the diagnosis can be surprisingly difficult unless a herd is undergoing a primary infection, in which case faecal samples should confirm the presence of $D$. viviparus larvae, although infections commonly remain patent for only 2-3 months post-infection in young animals (Michel, 1962) and even less one to two months - in cows (Fiedor et al., 2009). Blood or milk samples will also be seropositive after a primary infection, providing the challenge is sufficient: $>25$ larvae (Strube et al., 2017). Other than in new infections in naïve animals, antibodies to $D$. viviparus are of limited diagnostic value as they can be detected for at least 6 months after first exposure (Cornelissen et al., 1997; Fiedor et al., 2009), even in the absence of challenge, so positive results simply mean that the animal/herd has been infected sometime in the past and is not necessarily infected at the time of sampling. Furthermore, re-infections in dairy cattle can result in lower or no antibody responses and so seropositivity can be transient in nature (Strube et al., 2017).

Recent research has shown that in dairy cows, there were no significant associations between the presence of faecal lungworm larvae, seropositivity to $D$. viviparus and clinical signs (coughing) of PB (May et al., 2018). There was however a significant $(P<0.05)$ association between cows with a patent lungworm infection and daily milk yield, which was $1.6 \mathrm{~kg} / \mathrm{cow} /$ day less than controls. Only a small proportion (5\%) of coughing cows had patent lungworm infections, and so the emphasis is also on differential diagnoses of respiratory disease in groups of adult cattle, focussing on bacterial, mycoplasma or viral infections, particularly infectious bovine rhinotracheitis (IBR). However, given that, rather than respiratory signs, a large reduction in daily milk yield was associated with patent PB, it could be argued that a sudden drop in milk yield at either the individual cow or herd level, especially during the second half of the grazing season, should raise suspicions of lungworm, particularly if no other cause of poor yield is apparent.

Helminth Co-infections

It is commonplace to consider parasite infections species-by-species, yet, because of the ubiquity of parasitic gastroenteritis (PGE) caused by Ostertagia ostertagi in cattle of all ages and in conjunction with Cooperia oncophora in FGS animals, lungworm infections are typically superimposed on PGE. This pattern is evident in surveys based on bulk milk tank testing for antibodies to various helminth parasites in dairy herds (Bennema et al., 2009; Bloemhoff et al., 2015; Frey et al., 2018). This makes it difficult to attribute observed reductions in milk yield to either lungworm or 0 . ostertagi - or both (Dank et al., 2015). Under experimental conditions in naïve calves, co-infections with Ostertagia ostertagi and Cooperia oncophora result in a more profound impact from dictyocaulosis, manifest as higher establishment of lungworm burdens and increased larval shedding (Figure 6), compared to mono-infections with $D$. viviparus alone (Kloosterman et al., 1989). An additional potential role for PGE in dictyocaulosis is that transmission of $D$. viviparus has been shown to be enhanced when faeces are in semi-liquid form and dispersed thinly over pasture (Rose and Michel, 1957); diarrhoea is commonly associated with PGE. These observations are relevant to the management of PB in the field, where simultaneous control PGE would seem to be desirable, particularly in young cattle (Michel and Parfitt, 1956). 


\section{Closing remarks}

Dictyocaulosis in cattle, in all its manifestations, has a profound impact on infected individuals, the herd and the farm with self-evident losses through mortality, reduced growth rates and milk yield, costs associated with treatment of clinical cases and control measures (Holzhauer et al., 2011). An understanding of the underlying pathology and immune responses to $D$. viviparus, considered within an epidemiological framework, can help clinicians understand disease processes and sequelae so that recommendations for therapy and prevention can be logical and evidence-based; this will be the subject of the second article on lungworm.

\section{References}

APHA, 2016. Cattle respiratory disease in late summer and autumn. Vet Rec 179, 328.

Bennema, S., Vercruysse, J., Claerebout, E., Schnieder, T., Strube, C., Ducheyne, E., Hendrickx, G., Charlier, J., 2009. The use of bulk-tank milk ELISAs to assess the spatial distribution of Fasciola hepatica, Ostertagia ostertagi and Dictyocaulus viviparus in dairy cattle in Flanders (Belgium). Vet Parasitol 165, 51-57.

Bloemhoff, Y., Forbes, A., Good, B., Morgan, E., Mulcahy, G., Strube, C., Sayers, R., 2015. Prevalence and seasonality of bulk milk antibodies against Dictyocaulus viviparus and Ostertagia ostertagi in Irish pasture-based dairy herds. Vet Parasitol 209, 108-116.

Boon, J.H., Kloosterman, A., Breukink, M., 1984. Parasitological, serological and clinical effects of continuous graded levels of Dictyocaulus viviparus inoculations in calves. Vet Parasitol 16, 261-272.

Borgsteede, F.H., van der Linden, J.N., Cornelissen, J.B., Gaasenbeek, C.P., Ascher, F., 1998. Effect of three sustained-release devices on parasitic bronchitis in first year calves. Vet Rec 142, 696699.

Cornelissen, J.B., Borgsteede, F.H., van Milligen, F.J., 1997. Evaluation of an ELISA for the routine diagnosis of Dictyocaulus viviparus infections in cattle. Vet Parasitol 70, 153-164.

Crawshaw, W.M., Smith, J.H., 2003. Dictyocaulosis in housed five- to eight-month-old dairy-bred calves. Vet Rec 153, 149-150.

Cunningham, M.P., Jarrett, W.F.H., McIntyre, W.I.M., Urquhart, G.M., 1956. The carrier animal in bovine parasitic bronchitis: a knackery and farm survey. Vet Rec 68, 141-143.

Dank, M., Holzhauer, M., Veldhuis, A., Frankena, K., 2015. Association between Dictyocaulus viviparus status and milk production parameters in Dutch dairy herds. J Dairy Sci 98, 77417747.

David, G.P., 1993. Increased prevalence of husk. Vet Rec 133, 627.

David, G.P., 1997. Survey on lungworm in adult cattle. Vet Rec 141, 343-344.

Doncaster, C.C., 1981. Observations on relationships between infective juveniles of bovine lungworm, Dictyocaulus viviparus (Nematoda: Strongylida) and the fungi, Pilobolus kleinii and P. crystallinus (Zygomycotina: Zygomycetes). Parasitology 82, 421-428.

Downey, N.E., 1965. Live-weight changes and eosinophil responses in calves vaccinated against parasitic bronchitis and exposed to pasture infestation. Vet Rec 77, 890-895.

Duncan, J.L., Armour, J., Bairden, K., Urquhart, G.M., Jorgensen, R.J., 1979. Studies on the epidemiology of bovine parasitic bronchitis. Vet Rec 104, 274-278.

Eysker, M., Claessens, E.W., Lam, T.J., Moons, M.J., Pijpers, A., 1994. The prevalence of patent lungworm infections in herds of dairy cows in The Netherlands. Vet Parasitol 53, 263-267.

Fiedor, C., Strube, C., Forbes, A., Buschbaum, S., Klewer, A.M., von Samson-Himmelstjerna, G., Schnieder, T., 2009. Evaluation of a milk ELISA for the serodiagnosis of Dictyocaulus viviparus in dairy cows. Vet Parasitol 166, 255-261.

Forbes, A.B., 2012. Parasite myth busting. Cattle Practice 20, 128-136. 
Forbes, A.B., 2017. Grassland management and helminth control on cattle farms. Livestock 22, $12-$ 17.

Forbes, A.B., Huckle, C.A., Gibb, M.J., Rook, A.J., Nuthall, R., 2000. Evaluation of the effects of nematode parasitism on grazing behaviour, herbage intake and growth in young grazing cattle. Vet Parasitol 90, 111-118.

Forbes, A.B., Rice, B.J., 2000. Patterns of parasitic nematode infection and immunity in dairy heifers treated with ivermectin in a sustained-release bolus formulation either at turnout or in the middle of the grazing season. Vet Rec 147, 295-297.

Frey, C.F., Eicher, R., Raue, K., Strube, C., Bodmer, M., Hentrich, B., Gottstein, B., Marreros, N., 2018. Apparent prevalence of and risk factors for infection with Ostertagia ostertagi, Fasciola hepatica and Dictyocaulus viviparus in Swiss dairy herds. Vet Parasitol 250, 52-59.

Gupta, R.P., Gibbs, H.C., 1970. Epidemiological invetsigations on Dictyocaulus vivparus (Bloch, 1782) infection in cattle. The Canadian Veterinary Journal 11, 149-156.

Hoglund, J., Viring, S., Tornqvist, M., 2004. Seroprevalence of Dictyocaulus viviparus in first grazing season calves in Sweden. Vet Parasitol 125, 343-352.

Holzhauer, M., van Schaik, G., Saatkamp, H.W., Ploeger, H.W., 2011. Lungworm outbreaks in adult dairy cows: estimating economic losses and lessons to be learned. Vet Rec 169, 494.

Jarrett, W.F.H., McIntyre, W.I.M., Jennings, F.W., Mulligan, W., 1957a. The Natural History of Parasitic Bronchitis with notes on Prophylaxis and Treatment. Vet Rec 69, 1329-1340.

Jarrett, W.F.H., McIntyre, W.I.M., Urquhart, G.M., 1954. Husk in Cattle. Vet Rec 66, 665-676.

Jarrett, W.F.H., McIntyre, W.I.M., Urquhart, G.M., 1957b. The pathology of experimental bovine parasitic bronchitis. J Path Bact 73, 183-193.

Jorgensen, R.J., 1980a. Dictyocaulus viviparus: migration in agar of larvae subjected to a variety of physicochemical exposures. Exp Parasitol 49, 106-115.

Jorgensen, R.J., 1980b. Epidemiology of bovine dictyocaulosis in Denmark. Vet Parasitol 7, 153-167.

Jorgensen, R.J., Ronne, H., Helsted, C., Iskander, A.R., 1982. Spread of infective Dictyocaulus viviparus larvae in pasture and to grazing cattle: experimental evidence of the role of Pilobolus fungi. Vet Parasitol 10, 331-339.

Kloosterman, A., Frankena, K., Ploeger, H.W., 1989. Increased establishment of lungworms (Dictyocaulus viviparus) in calves after previous infections with gastrointestinal nematodes (Ostertagia ostertagi and Cooperia oncophora). Vet Parasitol 33, 155-163.

Kooyman, F.N., Ploeger, H.W., Hoglund, J., JP, V.A.N.P., 2007. Differential N-glycan- and proteindirected immune responses in Dictyocaulus viviparus-infected and vaccinated calves. Parasitology 134, 269-279.

Kroonen, J.E., Verstegen, M.W., Boon, J.H., van der Hel, W., 1986. Effect of infection with lungworms (Dictyocaulus viviparus) on energy and nitrogen metabolism in growing calves. Br J Nutr 55, 351-360.

Laabs, E.M., Schnieder, T., Strube, C., 2012. In vitro studies on the sexual maturation of the bovine lungworm Dictyocaulus viviparus during the development of preadult larvae to adult worms. Parasitol Res 110, 1249-1259.

May, K., Brügemann, K., König, S., Strube, C., 2018. The effect of patent Dictyocaulus viviparus (re)infections on individual milk yield and milk quality in pastured dairy cows and correlation with clinical signs. Parasit Vectors 11, 24.

McLeonard, C., Van Dyk, J., 2017. Controlling lungworm disease (husk) in dairy cattle. In Practice 39, 408-419.

Michel, J.F., 1957. Further experiments on the epidemiology of parasitic bronchitis in calves. Vet Rec 69, 1118-1121.

Michel, J.F., 1962. Studies on resistance to Dictyocaulus infection. IV. The rate of acquisition of protective immunity in infection of $D$. viviparus. J Comp Pathol 72, 281-285.

Michel, J.F., 1969. The control of some nematode infections in calves. Vet Rec 85, 326-329. 
Michel, J.F., Coates, G.H.D., 1958. An experimental outbreak of husk among previously parasitised cattle. Vet Rec 70, 554-556.

Michel, J.F., Mackenzie, A., 1965. Duration of the Acquired Resistance of Calves to Infection with Dictyocaulus viviparus. Res Vet Sci 6, 344-395.

Michel, J.F., Ollerenshaw, C.B., 1963. Parasitic bronchitis, In: Worden, A.N., Sellers, K.C., Tribe, D.E. (Eds.) Animal Health, Production and Pasture. Longmans, Green \& Co Ltd., London, pp. 458478.

Michel, J.F., Parfitt, J.W., 1956. An experimental study of the epidemiology of parasitic bronchitis in calves. Vet Rec 68, 706-710.

Michel, J.F., Shand, A., 1955. A field study of the epidemiology and clinical manifestations of parasitic bronchitis in adult cattle. Vet Rec 67, 249-266.

Msolla, P.M., Allan, E.M., Selman, I.E., Wiseman, A., 1983. Reactivation and shedding of bovine herpesvirus 1 following Dictyocaulus viviparus infection. J Comp Path 93, 271-274.

Nelson, M., 1977. Where do lungworms go in wintertime? Vet Rec 101, 248.

Oakley, G.A., 1977. Overwinter survival of Dictyocaulus viviparus. Vet Rec 101, 187-188.

Ploeger, H.W., Borgsteede, F.H., Sol, J., Mirck, M.H., Huyben, M.W., Kooyman, F.N., Eysker, M., 2000. Cross-sectional serological survey on gastrointestinal and lung nematode infections in first and second-year replacement stock in the Netherlands: relation with management practices and use of anthelmintics. Vet Parasitol 90, 285-304.

Ploeger, H.W., Eysker, M., 2000. Simulating Dictyocaulus viviparus infection in calves: the parasitic phase. Parasitology 120 Suppl, S3-15.

Ploeger, H.W., Eysker, M., 2002. Protection against and establishment of Dictyocaulus viviparus following primary infection at different dose levels. Vet Parasitol 106, 213-223.

Ploeger, H.W., Holzhauer, M., 2012. Failure to eradicate the lungworm Dictyocaulus viviparus on dairy farms by a single mass-treatment before turnout. Vet Parasitol 185, 335-338.

Ploeger, H.W., Verbeek, P.C., Dekkers, C.W., Strube, C., Van Engelen, E., Uiterwijk, M., Lam, T.J., Holzhauer, M., 2012. The value of a bulk-tank milk ELISA and individual serological and faecal examination for diagnosing (sub)clinical Dictyocaulus viviparus infection in dairy cows. Vet Parasitol 184, 168-179.

Robinson, J., 1962. Pilobolus spp. and the translation of the infective larvæ of Dictyocaulus viviparus from fæces to pastures. Nature 193, 353.

Rose, J.H., 1956. The bionomics of the free-living larvae of Dictyocaulus viviparus. J Comp Path 66, 228-240.

Rose, J.H., Michel, J.F., 1957. Quantitative studies on the contamination of pasture herbage with husk worm larvae. J Comp Path 67, 57-68.

Saatkamp, H.W., Eysker, M., Verhoeff, J., 1994. Study on the causes of outbreaks of lungworm disease on commercial dairy farms in The Netherlands. Vet Parasitol 53, 253-261.

SAC, 2018. Surveillance September 2017: Parasitic diseases. Vet Rec 182, 71.

Schnieder, T., Bellmer, A., Tenter, A.M., 1993. Seroepidemiological study on Dictyocaulus viviparus infections in first year grazing cattle in northern Germany. Vet Parasitol 47, 289-300.

Schnieder, T., Epe, C., Von Samson-Himmelstjerna, G., Kohlmetz, C., 1996. The development of protective immunity against gastrointestinal nematode and lungworm infections after use of an ivermectin bolus in first-year grazing calves. Vet Parasitol 64, 239-250.

Schnieder, T., Kaup, F.J., Drommer, W., 1991. Morphological investigations on the pathology of Dictyocaulus viviparus infections in cattle. Parasitol Res 77, 260-265.

Schunn, A.M., Conraths, F.J., Staubach, C., Frohlich, A., Forbes, A., Schnieder, T., Strube, C., 2013. Lungworm Infections in German dairy cattle herds--seroprevalence and GIS-supported risk factor analysis. PloS one 8, e74429.

Shoo, M.K., Wiseman, A., Allan, E.M., Dalgleish, R.G., Gibbs, H.A., Al-Hendi, A.B., Selman, I.E., 1990. Distribution of Pasteurella haemolytica in the respiratory tracts of carrier calves and those subsequently infected experimentally with Dictyocaulus viviparus. Res Vet Sci 48, 383-385. 
Spedding, C.R., Michel, J.F., 1957. The study of the transmission of the cattle lungworm (Dictyocaulus viviparus) in relation to pasture conditions. Parasitology 47, 153-159.

Strube, C., Springer, A., Schunn, A.M., Forbes, A.B., 2017. Serological lessons from the bovine lungworm Dictyocaulus viviparus: Antibody titre development is independent of the infection dose and reinfection shortens seropositivity. Vet Parasitol 242, 47-53.

Taylor, S.M., Kenny, J., Edgar, H.W., Mallon, T.R., Canavan, A., 2000. Induction of protective immunity to Dictyocaulus viviparus in calves while under treatment with endectocides. Vet Parasitol 88, 219-228.

Taylor, S.M., Kenny, J., Edgar, H.W., Whyte, M., 1997. Protection against Dictyocaulus viviparus in second year cattle after first year treatment with doramectin or an ivermectin bolus. Vet Rec 141, 593-597.

Tilling, O., 2014. Lungworm in cattle in the United Kingdom: a review. Livestock 19, 210-215.

Verhoeff, J., Wierda, A., Boon, J.H., 1988. Clinical signs following experimental lungworm infection and natural bovine respiratory syncytial virus infection in calves. Vet Rec 123, 346-350.

Wapenaar, W., Barkema, H.W., Eysker, M., O'Handley, R.M., 2007. An outbreak of dictyocaulosis in lactating cows on a dairy farm. J Am Vet Med Assoc 231, 1715-1718.

\section{Key points}

- The biology of lungworm can result in rapid changes in pasture larval populations and hence the risk of infection and disease within the same grazing season.

- The outcome of exposure to infection depends on the magnitude of the pasture larval challenge and the immune status of the cattle that are grazing there.

- Changes in dairy systems and husbandry over the last 30 years may have destabilised the acquisition and maintenance of immunity to Dictyocaulus viviparus, whether through natural exposure or vaccination.

- Treatment and control options for lungworm can be best dissected and discussed with farmers with knowledge of key aspects of immunobiology and epidemiology, contextualised for each farm each year. 


\section{Figures}

1. Five-year rolling average of lungworm submissions showing seasonality

2. Pilobolus spp on dung showing ripe, black sporangia on top of a fluid-filled vesicle, which provides the propelling force when it bursts, supported on sporangiophores (stalks).

3. Erratic pattern of pasture larval populations over second half of grazing season on field setstocked with naïve calves from turnout

4. Adult Dictyocaulus viviparus in the bronchi of a terminal case, showing obstruction of airways and some associated pathology, including emphysema.

5. Dyspnoeic young dairy cow with patent lungworm infection (courtesy of Chris Watson)

6. Co-infection of Dictyocaulus viviparus with Ostertagia ostertagi and Cooperia oncophora results in higher populations of lungworms in the host and higher concentration of larvae in the faeces 